\title{
The Protection of the Economic Benefits of Audio-Visual Works - A Focus on the Information Network Transmission Right
}

\author{
Qiuhao Shen ${ }^{1 *}$, Fan Yang ${ }^{2}$ \\ ${ }^{1}$ Zhejiang A \& F University, Hangzhou 311300, Zhejiang, China \\ ${ }^{2}$ Shaanxi Kuangda Law Firm, Yan'an 716000, Shaanxi, China \\ Email: 2448524076@qq.com
}

\begin{abstract}
This article addresses the intellectual property rights and other legal protections associated with the use of communication networks to transmit audio-visual and interactive content. The right to disseminate original content is guaranteed as a basic intellectual property right. The digital content rights holder is entitled to economic benefits derived from selling or licensing access to that content. Any unauthorized use or transmission of audio-visual content constitutes infringement and renders the infringer subject to legal consequences. At the same time, it is necessary to consider the intent of the actor and whether the unauthorized use has had negative economic consequences for the rights holder. Audio-visual content distributed via ICT can be further protected by clear and detailed appropriate use specifications and technological solutions that prevent unauthorized use while still permitting users to benefit from the access made possible by today's powerful and ubiquitous communication networks.
\end{abstract}

Keywords: information network transmission right, audio-visual works, safe haven rules, interactivity propagation

\section{Introduction}

Movies and TV dramas are cultural and artistic works popular among the public. Nowadays, these works can be appreciated both through TV and the Internet. "Modern network technology provides a variety of methods for recording, storing, and transmitting such works, and works can be easily transmitted through digital technology" (Chen, 2013). ${ }^{[1]}$ Such a situation makes it even harder to protect audio-visual works. China Internet Network Information Center (CNNIC) released the Internet Statistics Report in February: "Since December 2020, the number of Internet users in China has increased to 989 million, with the Internet penetration rate of 70.4\%." Meanwhile, the number of mobile Internet users recorded 986 million, an increase of 88.85 million from March 2020. In view of the current diversified forms of online media, it is likely that more and more TV series will be broadcast exclusively on apps such as iQiyi, Youku, Tencent Video, and Sohu Video in the future. In this context, it will be more important to focus on issues like the security of the video sources that involve the protection of the information network transmission right of audio-visual works. In addition, media producers and broadcasting platforms tend to bear heavier responsibility regarding the protection of data and information rights and interests. Therefore, it appears to be extremely important to conduct theoretical research on the legal protection of the information network transmission right of audio-visual works. This thesis attempts to study the infringement and protection of audio-visual works in the information network environment by analyzing the characteristics of the information network transmission of audio-visual works and the provisions of China's Intellectual Property Law in this field.

\section{Definition of audio-visual works}

\subsection{The concept of audio-visual works}

Literally speaking, "Shi" means vision, and can also be considered as a television work; "Ting" refers to hearing, which reflects the complex nature of such works. Regarding the concept of audio-visual works, the third draft of the revised Copyright Law of China stipulates: "Audio-visual works mainly include movies, TV series and film works produced by other methods." Regarding the sentence of "works produced by methods similar to the production of a movie", it is necessary to appropriately expand its connotation. In other words, works should be recognized as audio-visual works as long as their perpetrators take a certain filming behavior in the process of production with creative expression. For works such as micromovies, web dramas, and webcasts produced through the video editing software on a computer and transmitted over the Internet, they have no so-called producers, and sometimes even no fixed carriers. However, their production process reflects the author's choice and arrangement to a certain extent. Therefore, it is more conducive to its protection to define it as an 
audio-visual work, which means it is necessary to characterize it as an audio-visual work. Such a determination is conducive to facilitating the protection of "new types of works of the same family", while also taking into account the stability of legislation.

\subsection{The nature of audio-visual works}

\subsubsection{The attributes of multiple works of audio-visual works}

"As for the nature of audio-visual works, the academic circles give discordant opinions, mainly including three viewpoints of collaborative works, derivative works, and hired works" (Zeng, 2013). ${ }^{[2]}$ In categorizing audio-visual works, it is necessary to focus on its creative characteristics, transmission forms and material carriers. In view of the complexity of the production and organization of audio-visual works, they cannot be treated as derivative works, nor as collaborative works. The reason lies in that audio-visual works show different qualitative characteristics from different angles. First of all, from the perspective of the content, audio-visual works often contain a variety of artistic works such as text, music, dance, art, and pictures to achieve good artistic performance. From this perspective, audio-visual works have the characteristics of collaborative works. Secondly, the production of an audio-visual work also requires the producer apart from the creation and support staff. The copyright of audio-visual works is ultimately enjoyed by the producer, and other people involved in the creation have the right to be paid, which means that such works also show certain characteristics of hired works. In some common law countries, audio-visual works are classified as hired works. Finally, it is entirely possible that an audio-visual work is a derivative work. It can interpret other works by filming a movie, which means it is also a derivative work.

\subsubsection{To clarify the nature of audio-visual works means to protect them}

It means to clarify the rights of the author and further protect works by clarifying their nature. Audio-visual works integrate many other types of works in the creation process, which requires a "three-dimensional mode" of protection. For example: person A creates the picture book M, and person B rewrites it into a movie outline with the approval of A. Then the producer $\mathrm{C}$, after obtaining the consent of $\mathrm{A}$ and $\mathrm{B}$, makes the work into a movie of the same name of $\mathrm{M}$. According to Article 15 of the Copyright Law, person D can make and release Opera A in accordance with Movie A with the permission of $\mathrm{C}$ and by specifying existing works and author names. In addition, he or she only needs to ensure not to infringe the copyright of upstream authors (A, B) when exercising the rights of the new work. In this way, the rights of upstream authors (A, B) of movie work A have only been generally protected, and their control over the corresponding upstream works cannot be highlighted. Therefore, the protection of audio-visual works should consider the conditions of the multiple types of existing works, thus fully protecting the rights and interests of upstream authors of works in this category.

\section{The information network transmission right of audio-visual works}

\subsection{The information network transmission right of audio-visual works}

"As early as 1995, Intellectual Property and National Information Infrastructure of the United States mentioned that online transmission combines reproduction and distribution, which exercises both the right of reproduction and the right of distribution. Therefore, it is hoped to expand the denotation of the right of distribution and include digital network transmission" (Jin \& Shi, 2009). ${ }^{[3]}$ The European Union put forward the concept of "the right of transmission to the public", which reflects copyright owner's control over the transmission of works on the Internet" (Li, 2003). ${ }^{[4]}$

"Article 8 of the World Intellectual Property Organization Copyright Treaty stipulates: 'Authors of literary and artistic works shall have exclusive rights to authorize the transmission of their works to the public by wired or wireless means, including making their works available to the public. In this way, members of the public can obtain these works at a place and time selected by themselves'." The Copyright Law of China revised in 2001 added this right, and then the Regulations on the Protection of the Information Network Transmission Right of audio-visual works specifically stipulated the protection and restriction of this right" (Zhang, 2015). ${ }^{[5]}$ Subsequently, the third draft of the revised Copyright Law was released on October 30, 2012, which includes new regulations on the information network transmission right.

First of all, the information network transmission right is significantly characterized by property nature, and authors can obtain economic benefits by exercising or authorizing the exercise of this right. Secondly, the information network transmission right can also be categorized as an absolute right. Anyone who is not specific has the obligation not to hinder the right holder from exercising his or her rights. However, it should be noted that it is not necessary for the public to be exposed to the work at any time and place of their choice. Professor Wang Qian, a well-known scholar, suggested: "The time and place chosen by the individual cannot be absolutely understood as that the individual can choose any time within 24 hours and any corner of the world at will. The behavior is untenable if one denies the actions of the operator providing works on-demand in a local area network such as Internet cafes on the grounds that the public cannot choose a place at will 
to obtain the work (Wang, 2011)."[[]

\subsection{Interactivity of the information network transmission right}

Attention should be paid to more than the literal meaning of the information network transmission right to understand its true meaning. Interactivity is particularly important for the information network transmission right. It is a necessity to focus on the interactivity of transmission behaviors to judge whether one infringes on the information network transmission right.

Some people suggested: "The biggest difference between the information network transmission right and traditional broadcasting, such as broadcasting, lies in that "the public get on-demand (Zhang, 2017)."[7] Compared with the "passive reception by users" and "point-to-multipoint" characteristics of traditional broadcasting right, the information network transmission right offers the mode of "active contact by user" and "point-to-point (P2P)". For example: A certain website stores movie A on the server of its own website without authorization, and any network user can download or watch the movie A on the website at any time. In this case, Website A infringes on the information network transmission right of the audio-visual work.

In general, if the author exercises or authorizes the information network transmission right of the work, we, as the public, can upload, download, repost, and participate in editing the work at the chosen time and place. In this way, we can get in touch with works more conveniently and quickly through multimedia equipment.

So, does the unauthorized "timed transmission" of audio-visual works infringe on the information network transmission right? For example, in the case of Anle Company v. Shiyue Company, the information network transmission right of the movie Fearless in the mainland area is enjoyed by Anle Company. On February 28, 2008, Shiyue Company provided an online playback service of the movie Fearless on its own video website. The playback time displayed on the website was 07:18, 08:58, 10:37, 12:16, 13:56, 15:35, 17:15 and 18:54 respectively. The right holder filed a lawsuit with the BJ2ZY on the grounds of copyright infringement. In the trial of the case, "the court did not directly determine that Shiyue Company infringed on the information network transmission right of the work. Instead, it determined that its conduct of providing regular online broadcasting services of the film Fearless to the public violated Anle Company's copyright to 'transmit to the public through wired and wireless methods in accordance with a pre-arranged timetable and provide the right to regularly broadcast the work online'. Therefore, Shiyue Company shall bear the civil liability for stopping the infringement and compensating for losses in accordance with the law."

Others also proposed that: "The so-called 'timed broadcasting' does not change the nature of transmission, and it falls within the scope of the regulation of the network transmission right (Jiao, 2009)." "[8] However, unauthorized "timed broadcasting" of audio-visual works violates that "other rights that should be enjoyed by copyright owner" stipulated in Article 9 of China's Copyright Law. For example, website B is not authorized to play TV series A at 8 o'clock every night. In such a case, network users can neither download nor play at selected time. Such a conduct shows no interactivity feature of information network transmission. Therefore, it is unreasonable to characterize it as an infringement of the information network transmission right of TV series. On the other hand, it is able to judge the case more flexibly and accurately to categorize the behavior of timed broadcasting to "other rights that should be enjoyed by the copyright owner".

\section{Determination of the infringement of the information network transmission right of audio-visual works}

Behaviors of the infringement of audio-visual works are mainly concluded as follows: "leak" + "transmission", abuse of the "safe haven" system, and search engine behavior for searching for "pirated (illegal) audio-visual works websites" (ie QVOD mode) .

\subsection{Acts of "leak" + "transmission"}

\subsubsection{Video source leak}

"The video source obtainment" is a must for the infringement of the information network transmission right of audiovisual works. In recent years, it is a regular thing to find the leak of popular movies and TV series. For example, the trial version of the anti-corruption TV series In the Name of the People, which was hotly broadcasted in 2017, was leaked. The series have attracted much attention from the beginning. However, the show suffered the leak of its full episode on October 14, 2017. The e-commerce platform blatantly and illegally sold its resources. The illegal transmission and sale of the series through Baidu Pan, Weibo, WeChat, Taobao and other channels, has seriously violated the copyright of the copyright owner.

Two major illegal acts cause the leak of relevant sources. First, hackers steal from a regular video website that has a legal source by technical means, which is similar to the cracking method. In this way, the video sources that could be watched 
first only by purchasing the VIP qualifications in formal video websites are flooding various pirated websites and online cloud drives. Second, insiders sell the video sources. And once the pirated sources are uploaded to the relevant websites or personal online cloud drives, they would be spread quickly. The above two methods have a common feature, that is, obtaining the video sources first through illegal means. With the video sources, coupled with the cloud drive tool that is now popular on the Internet, a new method of infringing on the information network transmission right of audio-visual works has emerged. Specifically, it first obtains the video sources through illegal or legal means, and then shares or makes magnet links (seed) with cloud drives. As a result, pirated video sources flood in download tools and cloud drives.

How to define the behavior of obtaining video sources by technical means? Article 4 of China's Regulations on the Protection of the Information Network Transmission Right stipulates: "In order to protect the information network transmission right, the right holder may take technical measures. No organization or individual may deliberately avoid or destroy technological measures. No organization or individual may deliberately manufacture, import, or provide devices and components for the public that are mainly used to avoid or destroy technological measures. Organization or individual must not deliberately provide technical services for others to avoid or destroy technological measures." Nevertheless, it is still difficult for us to define it as an infringement of copyright, because it involves the right of reproduction of works. "Reproduction is the basic form of using works. The reason and fundamental purpose of the right of reproduction is to give authors or other copyright owners the right to control the provision of copies of works to the public, which is the essence of using work normally based on the right of reproduction (Ficsor, 2002)."[9]

Introduction to Copyright Law compiled by UNESCO proposes that: "Due to the development of digital technology, the storage of works in electronic media by digital technology shall also constitute 'copying' in the sense of copyright law. Some temporary or provisionary acts of copying (such as caching) shall be considered as the only exception that does not belong to copying, because its sole purpose is to spread on the network and it has no independent economic significance" (UNESCO, 2009). ${ }^{[5]}$ "China does not provide a clear legal definition of temporary copying in the Copyright Law and the Regulations on the Protection of Information Network Transmission Right, and the handling of this issue in judicial practice depends on individual cases" (Zhang, 2015). ${ }^{[10]}$

In short, the act of obtaining the video source through technical means violates the copyright of the work. An explanation of the purpose is required here. The right to copy the work at what time and in what way is enjoyed by the author, which means to better protect other related rights of the work. Without author's consent, it all violates the copyright of works by obtaining the video source through technical means for any purpose. And such acts is followed by the problem of the calculation of infringement losses. Since it is difficult to determine the actual adverse effects caused by the leak of the video source, it is necessary to delineate a reasonable liability boundary for the act, so as to prevent unreasonable expansion of liability.

\subsubsection{Transmission behavior}

The information network transmission right means to control the transmission behavior. With the video sources, it is a key issue of which way of transmission infringes the information network transmission right of audio-visual works.

What kind of uploading behaviors of users constitute an infringement of the information network transmission right of audio-visual works? Regarding this issue, it is not only difficult to find a reasonable boundary to delimit the infringement, but also difficult to detect the infringement. For example, actor A buys a genuine DVD of an audio-visual work B. Then A converts B into the network format with advertisements, and uploads it to his own cloud drive. A then provides paid sharing of the video source through Weibo, WeChat, Taobao and other platforms. Advertisers also pay for this. In this case, A's interactive transmission of the audio-visual work for commercial purpose undoubtedly constitutes infringement. From this case, it is easy to find that such infringement method is easy to operate but not easy to crack down.

The information network transmission right has a property nature. "Nowadays, artists, authors, or composers are basically invisible in copyright litigation. The main interest holders include publishers, video or music producers, and other media companies. And almost without exception, they all attempt to get money in return" (Bohannan \& Hovenkamp, 2012). ${ }^{[1]}$ Therefore, to examine whether the uploading and sharing behaviors of network users constitute infringement, it is a must to focus on their economic interests and purposes. For example, actor $\mathrm{C}$ buys a genuine audio-visual DVD D. Then $\mathrm{C}$ converts it into the network format and uploads it to his own cloud drive. Afterwards, $\mathrm{C}$ sends the audio-visual work to all his friends through cloud drive sharing. According to the nature of the information network transmission right, C's sharing behavior is characterized by interactivity and constitutes an infringement. However, there is something inappropriate with this determination, because $\mathrm{C}$ can share a genuine $\mathrm{CD}$ to a friend for free after buying it and he only achieves this purpose through technical means. More importantly, he does so not for commercial purpose, despite that such sharing behavior does harm the interests of the right holder. (The sales of this CD and the ratings of the audio-visual work will be affected). 
It should also be noted that $\mathrm{C}$ shares the audio-visual work not to all the public, but to the specific people (their friends), which is a relatively small harm to the audio-visual work. However, it does not mean that all gratuitous sharing behaviors are all not infringement. Instead, uploading and sharing for the purpose of malicious leak and pirated transmission constitutes infringement.

It is the most concealed to make and upload magnetic links (seed files) that can be downloaded by downloading tools. Such a method can even transmit illegal audio-visual work sources. Actors first create a magnetic link for users to download the sources of audio-visual works and then put the seed files in various forums, web pages, or their own Weibo or WeChat. Regarding the qualitative nature of such mode, as long as actors make and transmit magnetic links that can be downloaded by a downloading tool without the author's authorization, it constitutes the infringement of the information network transmission right of audio-visual works. First of all, from the characteristics of such behavior, it tries to facilitate and covertly transmit audio-visual works on the Internet. Secondly, this behavior is aimed at all the public. Those who are interested in certain types of audio-visual works can easily get the magnetic links of related audio-visual works through search engines. It exerts a great negative impact on holders of genuine audio-visual works to exercise their information network transmission right. Therefore, it is a must to strictly supervise this mode of transmitting audio-visual works.

\subsection{Abuse "safe haven" rule}

In the infringement mode mentioned above, the safe haven system also plays its role. After the leak, some video websites quickly store these illegal video sources in their own cloud drives. These small-scale video websites are large in number, but are difficult to manage because they register overseas. The "author's notification of removal" or the "red flag system" of presumptive infringement seems to be a drop in the bucket in this case. These pirated audio-visual works are usually easily accessed to by the public by means of cloud drives and magnetic links before the author's notification of removal. When Internet users search for popular audio-visual works, these small websites often tend to appear in the search results.

\section{3 "Websites that provide pirated/illegal audio-visual works" with search functions and links (QVOD mode)}

The essence of QVOD mainly lies in the provided technical services of "search" + "cache". In this way, most of the audio-visual works on the Internet can be cached in multimedia devices such as computers and mobile phones. Most of the audio-visual works that can be cached from QVOD are pirated sources provided by small-scale video websites. But some video resources are provided by formal video websites. As a result, the benefits generated in the process of information network transmission, such as advertising, belong to this video caching software. Worse still, it may even make the public mistakenly believe that this software legally owns the information network transmission right of related audio-visual works. Based on this kind of technical service, QVOD mainly profits by placing advertisements on the player interface and providing value-added services for VIP members. Reducing costs and increasing revenue are the main theme of almost all companies operating for thousands of years, and QVOD just did that. QVOD's unique P4P transmission technology can effectively reduce the operating costs of video websites, and custom buffered advertisements can effectively increase website online users and enable the website to achieve greater commercial value. Wang Xin (founder of QVOD) originally relied on these two ways to market QVOD. With the growing user base, QVOD's interface advertising became an important source of revenue. As a result, many webmasters applied QVOD's website building tools to set up a large number of pirated and obscene websites. QVOD's technical service mode already constituted a criminal offence because it involved the transmission of obscene and pornographic information. In addition, it also involved many issues of infringement of the copyright of audio-visual works. This thesis focuses on the analysis of how to infringe on the information network transmission right of audio-visual works under the QVOD mode.

As a playback software, QVOD did not actively provide pirated audio-visual works, but gathered websites that can watch pirated audio-visual works and provide local cached technical services by technical means. Information network transmission right is mainly controlled by an interactive transmission behavior. From this perspective, it seems that QVOD's technical services do not directly infringe the rights of related audio-visual works. However, others suggested that: "Knowing that an act constitutes copyright infringement, to induce, facilitate or substantially help others to commit infringement constitutes indirect infringement". Therefore, we must consider the technical services of QVOD as a whole. Although it is not an act of transmission to gather pirated audio-visual works sources and provide caching services, this act at least provides convenience to numerous infringing websites and facilitates the transmission of pirated audio-visual works. As a result, it expands the scope of infringement, and further harms the information network transmission right of the right holders. The infringement nature of this mode is self-evident.

It is true that technology is not guilty. However, QVOD, who owns technical means to block pirated or even obscene videos, allowed the transmission of pirated audio-visual resources, and even indulged in the deterioration of the situation. Such an attitude seems to imply users that "technical piracy is not a guilt". In fact, similar cases occurred in the United States 
long before the QVOD case. Regarding the question of whether the technology is guilty or not, the U.S. court gave a clear answer: "The company with technical services, who obviously can block this kind of piracy sharing, does not taken effective measures to stop it. Such a behavior constitutes a substantial help, and the company has to take responsibility." In fact, the General Principles of Civil Law that came into effect not long ago in China also stipulates regarding such situation. Article 86 of the General Principles of the Civil Law stipulates: "For-profit legal persons engaged in business activities shall abide by business ethics, maintain transaction safety, accept the supervision of the government and society, and assume social responsibilities." As a profitable legal person, QVOD provides this kind of technology service, which not only constitutes an infringement to the relevant rights holders of the works, but also has many adverse effects on society, especially in the field of our cultural life.

\section{Legal protection of the information network transmission right of audio-visual works}

\subsection{Source control}

\subsubsection{Establish an authoritative publishing platform for audio-visual works}

The key link of infringing on the information network transmission right of audio-visual works lies in "obtaining the video source", which implies the importance to strengthen the technical protection of the source of audio-visual works. Therefore, it is possible to establish an authoritative publishing portal for audio-visual works through technical means. If the right holder exercises the information network transmission right of the work, they can file and protect sources in the early stage through the portal. In cases when some small-scale video websites try to get deep links or pirate genuine audiovisual works, the portal can stop or technically block their behavior in time. Furthermore, the portal can also play a role in promoting genuine works.

\subsubsection{Crackdown illegally transmission websites}

Regarding the problem of the large and widespread distribution of pirated video websites, it is better to take "centralized processing" measures, rather than to block the pirated audio-visual work sources. We may use the "QVOD mode" reversely through technical means. That is to say, we can centrally rectify websites with sources similar to pirated audio-visual works, and issue collective warnings and removal notices. In this way, it can crack down numerous small video websites in an effective, quick, and comprehensive way. In addition, it can also prevent the further transmission of audio-visual works that are accidentally leaked on the Internet.

\subsubsection{Impose technical restrictions on uploading and reposting of online cloud drive users}

As mentioned above, the improper sharing and uploading behavior of individual Internet users may also infringe on the information network transmission right of audio-visual works. Although most Internet users upload and share not for profit, they also intangibly detract from the interests of copyright owners. In this regard, technical restrictions should be imposed on users' reposting and sharing behavior. To this end, relevant platforms and online cloud drive service providers can impose reasonable quota restrictions on users' reposting, sharing, and uploading behavior. In order to protect the normal use of users, the quota limit here can be set only for audio-visual works with relevant characteristics.

\subsection{Impose reasonable restrictions on "safe haven rules"}

"In the early draft of the DMCA, the 'safe haven rules' are simply stated as: the service provider shall not be liable for infringement or replacement liability."Article 71 of China's third revised draft of Copyright Law states: "If network service providers provide network users with pure network technical services such as storage, search, or linking, they shall not bear the censorship obligations related to copyright or related rights. As for others who use network services to infringe copyright or related rights, the right holders may notify the network service providers in writing and require them to take necessary measures such as deleting or link disconnecting. The network service providers shall not be liable for compensation if the network service providers take necessary measures in time after receiving the notice. The network service providers who fail to take necessary measures in time shall bear joint and several liability with the infringer." It can be seen from the above provisions that the application of the safe haven rules in the revised draft first exempts network service providers from censorship of uploaded content, which makes the transmission of pirated content a "temporary residence". Regarding this issue, the "red flag system" stipulates: "Internet service providers, who know that people use the service to infringe others' copyrights but fail to take necessary measures in a timely manner, shall bear joint and several liability with the infringer." It is worth noting that, if the leaked video sources, after being uploaded by network users, cannot be as eye-catching as a bright "red flag" like infringed works, they may be difficult to apply the red flag system, which will lead to a legal pirated audiovisual works exchange platform on the Internet. As a result, other Internet users can easily find related audio-visual works 
through the on-site search function provided by the Internet service providers.

"It is necessary to make it clear the assistance behavior that the network service providers provide automatic access and automatic transmission for the service objects" (Huang, 2012). ${ }^{[12]}$ Network service providers are undoubtedly helpers of infringements in this process. However, since they cannot prevent such infringements, they are exempted from liability, which is obviously unfair. Therefore, the responsibility of the network service providers should be appropriately increased. That is, the network service providers should make corresponding compensation based on the number of downloads and repost of the audio-visual works that have been notified to be removed, which can relatively reduce the loss of the right holders.

\subsection{Strictly crackdown on the "QVOD mode"}

First of all, more stringent supervision and filing should be imposed on software or Internet companies that provide local caching services for audio-visual works. In addition, it is necessary to regularly produce and publish "lists of audio-visual works that are prohibited from providing local caching or deep linking services" to them. Moreover, we should strengthen technical encryption and take other means to prevent the sources of genuine audio-visual works from being deeply linked or technically cracked. Secondly, in view of the characteristics of this transmission mode, we can set sensitive keywords, which can well block the function of such software to search for pirated audio-visual works, and hence help right holders to better control their right.

\section{Conclusion}

Rampant piracy means the deserted genuine works, in which case no one is willing to pay for excellent audio-visual works. After all, we are accustomed to the way of obtaining video resources for free. A large number of cracked and preemptive versions of audio-visual works can be easily obtained through simple Internet application technology, which is a big blow to the creation and development of audio-visual works. An audio-visual work integrates the ideas and arrangements of the people involved in the creation, and the producers also bear huge commercial risks for this. The judgment of the infringement of the information network transmission right of audio-visual works lies in its property and absoluteness, and it should be considered comprehensively from the involved purpose and the economic interests. In an era with advanced information network technology, the authorization to exercise the information network transmission right of audio-visual works has increasingly become an important means of income for creators and authors. The protection of the information network transmission right of audio-visual works is of vital importance to the development of such works.

\section{Acknowledgments}

This article is supported by 2020 General Project of Legal Research Project of Jiangsu Law Society (SFH2020B011).

\section{References}

[1] Chen Chen. Reflections on the improvement of China's information network transmission rights regulation[J]. Hebei Academic Journal. 2013; 33(3): 221-223.

[2] Zeng Mengqian. Research on the authors of audio - visual works and their ownership of copyrights: Based on the third amendment of Article 15 in China's Copyright Law[J]. Journal of Shaoyang University (Social Science Edition). 2013; 12(3): 49-54.

[3] Jin Xuejun, Shi Bisheng. Application of the right of communication through information network[J]. Chinese Journal of Law. 2009; 31(6): 106-116.

[4] Li Mingde. American intellectual property law[M]. Beijing: Law Press; 2003: 238.

[5] Zhang Ping. Intellectual property law[M]. Beijing: Peking University Press; 2015.

[6] Wang Qing. Copyright protection in the network environment[M]. Beijing: Law Press; 2011: 137.

[7] Zhang Jin. Communication behavior under information network[J]. Publishing Research. 2017; (2): 81-84.

[8] Jiao Heping. On the improvement of right of communication through information network in copyright law: From the perspective of torts concerning non-interactive communication through information network[J]. Science of Law - Journal of Northwest University of Political Science and Law. 2009; 27(6): 143-150.

[9] Ficsor, M. The law of copyright and the Internet[M]. Oxford: Oxford University Press; 2002.

[10] United Nations Educational, Scientific and Cultural Organization. The ABC of Copyright [M]. Paris: United Nations Educational, Scientific and Cultural Organization; 2009. Retrieved from http://www.unesco.org/new/en/media-services/single-view/news/abc_of_copyright/ 
[11] Bohannan, C., \& Hovenkamp, H. Creation without restraint: Promoting liberty and rivalry in innovation[M]. Oxford: Oxford University Press; 2012.

[12] Huang Min. The definition and legal analysis of communication behavior under indirect information network[J]. Science Technology and Law. 2012; (4): 93-96. 